\title{
Mental Health Literacy and the Belief in the Supernatural
}

\author{
Leslie Lim1, Justine Goh1, Yiong-Huak Chan², Shi-Hui Poon'1 \\ ${ }^{1}$ Department of Psychiatry, Singapore General Hospital, Republic of Singapore \\ ${ }^{2}$ National University Health System, National University of Singapore, Republic of Singapore \\ Email: leslie.lim.e.c@sgh.com.sg
}

Received 18 August 2015; accepted 6 October 2015; published 9 October 2015

Copyright (C) 2015 by authors and Scientific Research Publishing Inc.

This work is licensed under the Creative Commons Attribution International License (CC BY). http://creativecommons.org/licenses/by/4.0/

(c) (i) Open Access

\section{Abstract}

Objective: Mental health literacy affects treatment seeking. We compare literacy levels of psychiatric outpatients and a control group of outpatients seeking treatment for non-psychiatric disorders in the same hospital. We hypothesized higher levels of mental health literacy among psychiatric patients than controls, with younger age and higher educational levels associated with better literacy. We also hypothesized that there would be an inverse relationship between educational level and the belief in the supernatural causality of mental disorders. Methods: Literacy was estimated by showing psychiatric outpatients and a control group of non-psychiatric patients vignettes depicting a case of major depression and a case of generalised anxiety disorder. Their opinions regarding diagnosis, etiology, treatment, and attitudes towards mental health services were ascertained by structured questionnaires. Results: Psychiatric patients did not demonstrate superior mental health literacy compared to controls, with the exception of knowing where to obtain a psychiatric referral. Lower age and higher education levels of psychiatric patients were associated with better literacy. The higher the education level is, the less likely to attribute the causality of mental disorders to supernatural elements. Conclusion: This study highlights the need for a program of psycho-education targeting patients, their relatives, and the public.

\section{Keywords}

Mental Health Literacy, Age, Education Level, Belief in the Supernatural

\section{Introduction}

Low rates of help seeking among persons with mental disorders have been widely reported [1]-[4]. One of the reasons cited for this phenomenon is poor understanding of mental disorders, their etiology, symptoms, treat- 
ment, and prevention. Such knowledge is also termed "mental health literacy" [5]. There is growing evidence that poor mental health literacy (MHL) negatively impacts help-seeking behaviors and influences decisions regarding treatment and compliance [6]-[10].

Cultural factors also play a role in determining treatment preferences. For instance, the prevalent belief among people in Southeast Asia is to attribute mental illness causation to demonic spirits and supernatural elements [11]-[13]. Not surprisingly, some have preferred to consult traditional healers rather than seeking professional help from mental health services [1] [11] [13].

Most literacy research has assessed the general population. A notable exception was the study by Goldney et $a l$. [14] who utilised a case vignette describing depression to measure literacy in depressed patients. They found that depressed subjects' knowledge about depression was similar to that of non-depressed persons, despite the apparent familiarity of patients with the nature of the disorder and its treatment. In contrast, Furnham and Blythe, while not using the vignette method, found that lay persons without schizophrenia were able to display a higher degree of literacy if they had prior interactions with schizophrenia patients [15].

Our present study seeks to measure and compare the mental health literacy of patients undergoing psychiatric outpatient treatment to that of a control group of patients seeking treatment for non-psychiatric disorders in the same hospital. We hypothesized higher levels of mental health literacy among psychiatric patients compared to controls and that literacy would be positively associated with younger age and higher educational levels. We also hypothesized that there would be an inverse relationship between educational level and the belief in the supernatural causality of mental disorders.

\section{Methods}

\subsection{Participants and Procedure}

The study was conducted in the psychiatric outpatient clinic of a large general hospital in Singapore, a city state with a population of over 5 million. Over a period from 1 November 2014 to 31 March 2015, patients with anxiety and depressive disorders were interviewed by a trained research coordinator, who had access to their clinic records. We included patients between the ages of 21 to 75 years, who were able to understand written English or Mandarin, and who consented to participate in the study. Patients with organic mental conditions such as delirium or dementia, and psychosis were excluded. Control participants consisted of patients from other disciplines attending outpatient treatment from the same general hospital. Patients were approached with the approval of their respective hospital consultants, and subsequently interviewed if they were agreeable to participate in the study. The study was approved by the hospital's Institutional Review Board.

\subsection{Materials}

Participants were presented with two vignettes describing cases meeting Diagnostic and Statistical Manual of Mental Disorders, Fourth Edition, Text Revision (DSM-IV-TR) diagnostic criteria [16] for Major Depressive Disorder (MDD) and Generalised Anxiety Disorder (GAD) respectively. We used a structured questionnaire with a multiple choice response format. To assess recognition of MDD and GAD in the vignettes, participants were asked what type of illness they felt the subject in the vignette was suffering from (e.g. "physical illness/ mental illness/spiritual condition/none of the above/don't know”) and if they recognized a mental illness, what they thought the diagnosis was (e.g. "Acute stress disorder/Major Depression/Generalised Anxiety Disorder/ Panic Disorder/Obsessive-Compulsive Disorder/Schizophrenia/Others”).

Knowledge of interventions and treatments available was also tested by asking participants whether they felt certain interventions were needed to help resolve the problem, with interventions including "Physical exercise", "Diet”, "Psychotherapy", "Medication”, "Vitamins”, and "Exorcism”. We also enquired whether they held beliefs regarding the possible supernatural causation of mental disorders.

\subsection{Psychiatric Assessments}

We used the Mini-International Neuropsychiatric Interview (MINI) [17] to assess for any psychiatric morbidity in the controls and to confirm that the group of psychiatric patients and controls did not meet our exclusion criteria. 


\subsection{Statistical Analysis}

Data were analysed using the Statistical Package for the Social Sciences (SPSS) 22.0 program. Pearson's chisquared tests were conducted to identify any significant differences in demographic variables between the psychiatric patients and the control participants. One-way Analyses of Covariance (ANCOVA) were conducted to determine whether there was any significant difference in the mental health literacy scores of the psychiatric patients and control participants, while controlling for certain demographic variables. Significance was set at $p<$ 0.05 .

\section{Results}

A total of 131 patients, comprising 70 with psychiatric illness (mainly anxiety and depression) and 61 control subjects, were recruited into the study. Table 1 shows the characteristics of the sample. The mean age of the psychiatric patients was 51.6 years $(\mathrm{SD}=13.5)$ and the controls 44.8 years $(\mathrm{SD}=12.5)$. The differences in ages was significant according to a one-way Analysis of Variance (ANOVA), $F(1,129)=8.896, p=0.003$. There was also a significantly smaller percentage of psychiatric patients than control participants who were actively employed, $\chi^{2}(5, \mathrm{n}=131)=14.71, p=0.012$.

Each correct answer was given one mark. The scores for each component of mental health literacy were tallied. This yielded subtotals, from which the total composite score was obtained by addition of subtotal scores. Please refer to Table 2 which shows the component items and their maximum scores.

Table 1. Characteristics of the patients.

\begin{tabular}{|c|c|c|c|c|c|}
\hline & \multicolumn{2}{|c|}{ Psychiatric patients } & \multicolumn{2}{|c|}{ Non-psychiatric patients } & \multirow[b]{2}{*}{$p$-value } \\
\hline & $\begin{array}{l}\text { Number } \\
(N=70)\end{array}$ & $\begin{array}{c}\text { Percentage } \\
\text { (\%) }\end{array}$ & $\begin{array}{l}\text { Number } \\
(N=61)\end{array}$ & $\begin{array}{c}\text { Percentage } \\
\text { (\%) }\end{array}$ & \\
\hline Gender & & & & & 0.964 \\
\hline Male & 37 & 52.9 & 32 & 52.5 & \\
\hline Ethnicity & & & & & 0.931 \\
\hline Chinese & 62 & 88.6 & 51 & 83.6 & \\
\hline Non-Chinese & 8 & 11.4 & 10 & 16.4 & \\
\hline Education Level & & & & & 0.305 \\
\hline Primary to Secondary & 38 & 54.3 & 26 & 42.6 & \\
\hline Junior college/Polytechnic & 12 & 17.1 & 18 & 29.5 & \\
\hline Tertiary (University) & 20 & 28.6 & 17 & 27.9 & \\
\hline Employment Status & & & & & 0.012 \\
\hline Employed & 38 & 54.3 & 47 & 77.0 & \\
\hline Unemployed & 7 & 10.0 & 0 & 0 & \\
\hline Not in labour force & 25 & 35.7 & 14 & 23.0 & \\
\hline Marital Status & & & & & 0.172 \\
\hline Never married & 19 & 27.1 & 15 & 24.6 & \\
\hline Married & 41 & 58.6 & 42 & 68.9 & \\
\hline Divorced or separated & 5 & 7.1 & 4 & 6.6 & \\
\hline Widowed & 5 & 7.1 & 0 & 0 & \\
\hline Religion & & & & & 0.483 \\
\hline Christianity & 24 & 34.3 & 20 & 32.8 & \\
\hline Muslim & 2 & 2.9 & 6 & 9.8 & \\
\hline Buddhist or Taoist & 25 & 35.7 & 23 & 37.7 & \\
\hline Hindu & 2 & 2.9 & 1 & 1.6 & \\
\hline No religion & 17 & 24.3 & 11 & 18.0 & \\
\hline
\end{tabular}


Table 2. A description of the sub-score items.

$$
\begin{gathered}
\text { Vignette Identification (MDD) } \\
\text { Perceived type of illness } \\
\text { Name of disorder if perceived to be mental illness } \\
\text { Vignette Identification (GAD) } \\
\text { Perceived type of illness } \\
\text { Name of disorder if perceived to be mental illness } \\
\text { Description of persons with mental illness } \\
\text { Perceived descriptors of people with mental illness } \\
\text { Purpose of psychiatric medication } \\
\text { Perceived purpose of psychiatric medication } \\
\text { Side effects of psychiatric medication } \\
\text { Perceived side effects of psychiatric medication } \\
\text { Where to obtain a psychiatric referral } \\
\text { Perceived sources of psychiatric referral } \\
\text { Total score } \\
\text { Side effects of psychiatric medication } \\
\text { Where to obtain a psychiatric referral } \\
\text { Vignette Identification (MDD) } \\
\text { Description of persons with mental illness } \\
\text { Purpose of psychiatric medication } \\
\text { Sumporite }
\end{gathered}
$$

An ANOVA showed no significant differences in the sub-scores of mental health literacy between psychiatric patients and controls (all $p>0.05$ ). Since the ages and employment statuses of the control participants were found to be significantly different from that of the psychiatric patients, an ANCOVA was conducted to control for these two demographic variables, which were entered as covariates. Results of the ANCOVA showed no significant differences in all the sub-scores of mental health literacy between the psychiatric patients and control participants, with the only exception being knowledge of where to obtain a psychiatric referral, where psychiatric patients scored higher than the control group, $F(1,122)=7.25, p=0.008$.

There were no significant differences between the total composite scores of the psychiatric patients and control participants, $F(1,122)=1.66, p=0.200$.

However, simple linear regression analyses suggested an inverse relationship between age and total composite scores, which was significant for the psychiatric group $(p=0.046)$, but not significant for controls $(p=0.984)$. Additionally, there was a significant negative association between education level and belief in supernatural causes of both depression, $\chi^{2}(12, n=70)=40.47, p<0.001$, and GAD, $\chi^{2}(12, n=70)=40.17, p<0.001$, with the better educated less likely to subscribe to supernatural attributions. This negative association, however, was only statistically significant for the psychiatric patients, but not the controls.

When shown vignettes depicting anxiety and depression, the older psychiatric patients were not more likely to attribute the features of depression $(p=0.748)$, and anxiety $(p=0.559)$ to supernatural factors than the controls. There was no association between supernatural attributions of depression $(p=0.559)$ and anxiety $(p=0.085)$ and the total composite score of mental health literacy among the psychiatric patients.

Table 3 shows the results of the ANCOVA.

A one-way Analyses of Variance (ANOVA) to examine the relationships between demographic variables and the total composite score revealed that among psychiatric patients, scores differed significantly between different levels of education, $F(3,66)=5.041, p=0.003$. A Bonferroni post-hoc test revealed that those attaining Junior College/Polytechnic education (11.5 \pm 2.4 points, $p=0.042)$ and University level (11.1 \pm 4.0 points, $p=$ $0.049)$ had significantly higher total mental health literacy scores than those with Primary education (7.3 \pm 3.4 points). Thus, the better educated had a better grasp of MHL. 
Table 3. Means of each Sub-Score.

\begin{tabular}{ccccc}
\hline Sub-scores & \multicolumn{2}{c}{$\begin{array}{c}\text { Psychiatric patients } \\
(N=70)\end{array}$} & \multicolumn{2}{c}{$\begin{array}{c}\text { Non-psychiatric patients } \\
(N=61)\end{array}$} \\
\cline { 2 - 5 } & Mean & S.D. & Mean & 0.19 \\
Vignette Identification (MDD) & 1.22 & 0.17 & 1.09 & 0.17 \\
Vignette Identification (GAD) & 1.27 & 0.14 & 1.13 & 0.31 \\
Description of persons with mental illness & 1.19 & 0.27 & 1.22 & 0.29 \\
Purpose of psychiatric medication & 2.11 & 0.25 & 2.03 & 0.36 \\
Side effects of psychiatric medication & 1.74 & 0.31 & 1.67 & 0.19 \\
Where to obtain a psychiatric referral & & 0.16 & 1.59 & 8.72 \\
Total composite score & 2.00 & 9.53 & 0.67 & 0.78 \\
\hline
\end{tabular}

${ }^{*} F(1,122)=7.25, p=0.008$.

\section{Discussion}

Our study is unique in that it assesses psychiatric patients' ability to recognise features of common psychiatric conditions, whereas previous researchers only assessed such knowledge from members of the general population. An unexpected finding was that psychiatric patients did not demonstrate better literacy levels compared to non-psychiatric controls. This concurs with the findings of Goldney et al. [14] but is contrary to our hypothesis that psychiatric patients would display better literacy compared to non-psychiatric patients.

A recent study on breast cancer patients in this country has revealed poor mental health literacy levels in that less than half were able to identify anxiety and depressive features in vignettes shown to the patients [18]. However, the authors did not utilise a comparison group. In that study, patients indicated that they would turn to close family members for help with psychosocial distress, rather than seek consultation with mental health specialists. Over one half cited reasons such as fear and embarrassment for their disinclination to obtain help from mental health services [18].

This confirms the widespread notion of stigma being one of the barriers to help-seeking. In the case of those already receiving professional help, improved mental health literacy is an added advantage towards treatment adherence in the face of on-going negative public sentiments toward receiving psychiatric help.

Most studies from the West have revealed that between 35\% - 68\% respondents correctly identified the diagnosis in a vignette depicting a psychiatric condition [8] [19] [20]. When shown features of MDD, slightly over a third (about 35\%) of our patients gave the correct diagnosis, a quarter (25\%) thought there was no mental illness, and over a fifth (21\%) thought the diagnosis was an anxiety disorder. In the case of the GAD vignette, the results were fairly similar. Some $30 \%$ correctly identified the disorder, $14 \%$ thought there was no mental illness, while another $14 \%$ thought the vignette depicted a case of "stress". Those who failed to identify any mental illness or who dismissed an anxiety disorder as merely a case of "stress" might not see the need to seek psychiatric help. Some hold the belief that psychiatrists only treat the severely mentally ill, and consider "stress" not worthy of psychiatric attention. These would most likely turn to traditional healers or to close family members for help and support should they experience psychiatric symptoms.

Whether the correct identification would translate into professional help-seeking is not clear, with some authors of a literature review suggesting that increased health literacy does not necessarily lead to increased medication adherence [20]. One reason could be stigma as mentioned earlier, while another reason could be public misperception over the safety and efficacy of psychotropic medications [21] [22].

It was possible that those who identified no psychiatric diagnosis in the vignettes were influenced by cultural factors. For instance, in Southeast Asia, there is a strong belief in the role of supernatural agents (from witchcraft and black magic to evil spirits and divine anger) in bringing about mental disorders [11]-[13]. In fact, there was a trend, just short of significance $(p=0.056)$, for psychiatric patients to attribute the causality of the depressive condition to supernatural factors in contrast to the controls (see Table 4). The reasons for this are unclear. One possible explanation is that in families of psychiatric patients, in the absence of physical pathology, family members tend to attribute these symptoms to a spiritual affliction and advise consultation with traditional healers, thus influencing patients into making similar assumptions, as they had been culturally accustomed to believe. 
Table 4. Belief in supernatural causality of depression and anxiety.

\begin{tabular}{|c|c|c|c|c|c|}
\hline & \multicolumn{2}{|c|}{ Psychiatric patients } & \multicolumn{2}{|c|}{ Non-psychiatric patients } & \multirow[b]{2}{*}{$p$-value } \\
\hline & $\begin{array}{l}\text { Number } \\
(N=70)\end{array}$ & $\begin{array}{l}\text { Percentage } \\
\text { (\%) }\end{array}$ & $\begin{array}{l}\text { Number } \\
(N=61)\end{array}$ & $\begin{array}{c}\text { Percentage } \\
\text { (\%) }\end{array}$ & \\
\hline Belief in supernatural causality of depression & & & & & 0.056 \\
\hline Don’t know & 12 & 17.1 & 4 & 6.5 & \\
\hline Disagree & 55 & 78.6 & 57 & 93.4 & \\
\hline Agree & 3 & 4.3 & 0 & 0 & \\
\hline Belief in supernatural causality of anxiety & & & & & 0.760 \\
\hline Don’t know & 9 & 5.7 & 6 & 9.8 & \\
\hline Disagree & 58 & 82.9 & 54 & 88.5 & \\
\hline Agree & 3 & 4.3 & 1 & 1.6 & \\
\hline
\end{tabular}

However, for the control subjects, most of whom do not have psychiatric symptomatology and are clearly suffering from physical conditions, the question of supernatural causality would not have not arisen. Hence, the controls are less likely to attribute the depressive condition to the supernatural.

Our findings also suggest that while older psychiatric patients tended to have lower mental health literacy scores, age was not a determinant to supernatural attributions. Such beliefs are more likely held by those with less education. Another interesting finding was that belief in the supernatural did not seem to affect composite literacy scores. This suggests that good literacy is not mutually exclusive to cultural belief systems, in that they can co-exist in parallel in the same patient. Those with high literacy scores may still ascribe mental illness to spiritual factors.

Conversely, the higher the education level the less inclined to believe in supernatural explanations of illness etiology. Instead, the more highly educated showed better literacy levels, thus confirming our hypothesis. This contrasts with the control group where there was no association between education level and literacy. A possible explanation is that psychiatric patients had a vested interest in understanding more about their conditions than controls, and among the better educated, familiarity and ease of access to on-line information might have contributed to improved literacy levels.

An added clinical utility of mental health literacy is the ability to advise others suspected of having a psychiatric illness to seek the appropriate help, or what has been referred to as "psychiatric first-aid" [2]. Here, the patients' knowledge of where to obtain psychiatric help may be of benefit not only to themselves, but also to those they might be called upon to advise in the future.

There are certain strengths and limitations to our study worth mentioning. We have assessed the health literacy of a group of psychiatric outpatients and compared their responses with those from a control group of nonpsychiatric outpatients. To the best of our knowledge, the study of mental health literacy in patients and comparisons with a control group has seldom been performed in mental health literacy research. Owing to a modest sample size, our study may have been slightly underpowered; hence, certain observed differences between the two groups have only emerged as trends. We did not attempt to match the socio-demographic characteristics of both groups. This has yielded groups with different ages and employment statuses. In order to overcome this problem, we have applied the appropriate statistical tests to take into account these differences. The generalizability of our findings could be limited by the demographic characteristics—in particular, age, ethnicity, and education status of the cohort, and that it was based upon a single hospital study. Notwithstanding our limitations, we have managed to test and to confirm some of our hypotheses.

The finding that the level of psychiatric patients' mental health literacy was no better than that of the controls is a cause for great concern. This underlines the urgent need for a concerted program of psycho-education to patients, their relatives, and to the general public. Since the lesser educated and the older participants achieved the lowest scores on MHL, the program should, perhaps, target this group, as a start. Although some have found that increased literacy did not translate into treatment adherence [20], there are a number of reasons for regarding these findings with some caution. Firstly, the latter was a European study whose findings might not be generalizable to a Southeast Asian setting. Secondly, the association between literacy and treatment adherence has never been tested in this country. Therefore, we cannot assume that this intervention will result in failure even 
before it is started. Thirdly, we will certainly not expect treatment adherence or attitudes to treatment to spontaneously improve in the absence of any educational program being implemented. Conversely, should such a program be conducted, it will at least allow future research to assess its effects on literacy, attitudes, and helpseeking behavior.

\section{Acknowledgements}

The authors wish to thank Dr. Sharon Cohan Sung for valuable comments on an earlier draft of the manuscript. We gratefully acknowledge the Lee Foundation for sponsoring this study.

\section{References}

[1] Ng, T.P., Fones, C.S.L. and Kua, E.H. (2003) Preference, Need and Utilization of Mental Health Services, Singapore National Mental Health Survey. Australian and New Zealand Journal of Psychiatry, 37, 613-619.

[2] Jorm, A.F., Kitchener, B.A. and Mugford, S.K. (2004) Experiences in Applying Skills Learned in a Mental Health First Aid Training Course: A Qualitative Study of Participants' Stories. The WHO World Mental Health Survey Consortium: Prevalence, severity, and Unmet Need for Treatment of Mental Disorders in the World Health Organization World Mental Health Surveys. JAMA, 291, 2581-2590.

[3] Zachrisson, H.D., Rödje, K. and Mykletun, A. (2006) Utilization of health Services in Relation to Mental Health Problems in Adolescents: A Population Based Survey.BMC Public Health, 6, 34. http://dx.doi.org/10.4103/0253-7176.70510

[4] Topuzoğlu, A., Binba, T., Ulaş, H., Elbi, H,, Aksu T. F., Zağl1, N. and Alptekin, K. (2015) The Epidemiology of Major Depressive Disorder and Subthreshold Depression in Izmir, Turkey: Prevalence, Socioeconomic Differences, Impairment and Help-Seeking. Journal of Affective Disorders, 181, 78-86. http://dx.doi.org/10.3109/08039480903062950

[5] Jorm, A.F., Korten, A.E., Jacomb, R.A., et al. (1997) Mental Health Literacy: A Survey of the Public’s Ability to Recognise Mental Disorders and Their Beliefs about the Effectiveness of Treatment. Medical Journal of Australia, 166, 182186. http://dx.doi.org/10.1192/bjp.188.4.359

[6] Angermeyer, M.C. and Dietrich, S. (2006) Public Beliefs about and Attitudes towards People with Mental Illness: A Review of Population Studies. Acta Psychiatrica Scandinavica, 113, 163-179. http://dx.doi.org/10.1016/j.jad.2007.04.026

[7] Angermeyer, M.C., Matschinger, H. and Riedel-Heller, S.G. (1999) Whom to Ask for Help in a Case of a Mental Disorder? Preferences of the Lay Public. Social Psychiatry and Psychiatric Epidemiology, 34, 202-210. http://dx.doi.org/10.1093/occmed/kqn135

[8] Lauber, C., Nordt, C., Falcato, L. and Rössler, W. (2003) Do People Recognise Mental illness? Factors Influencing Mental Health Literacy. European Archives of Psychiatry and Clinical Neuroscience, 253, 248-251.

[9] Rüsch, N., Evans-Lacko, S.E., Henderson, C., Flach, C. and Thornicroft, G. (2011) Knowledge and Attitudes as Predictors of Intentions to Seek Help for, and Disclose, a Mental Illness. Psychiatric Services, 62, 675-678.

[10] Ten Have, M., de Graaf, R., Vilagut, G., Kovess, V., Alonso, J., et al. (2010) Are Attitudes towards Mental Health Help-Seeking Associated with Service Use? Results from the European Study of Epidemiology of Mental Disorders. Social Psychiatry and Psychiatric Epidemiology, 45, 153-163.

[11] Ng, B.Y. (2001) Till the Break of Day: A History of Mental Health Services in Singapore, 1841-1993. Singapore University Press, Singapore.

[12] Kua, E.H., Chew, P.H. and Ko, S.M. (1993) Spirit Possession and Healing among Chinese Psychiatric Patients. Acta Psychiatrica Scandinavica, 88, 447-450. http://dx.doi.org/10.1111/j.1600-0447.1993.tb03489.x

[13] Razali, S.M., Khan, U.A. and Hasanah, C.I. (1996) Belief in Supernatural Causes of Mental Illness among Malay Patients: Impact on Treatment. Acta Psychiatrica Scandinavica, 94, 229-233. http://dx.doi.org/10.1111/j.1600-0447.1996.tb09854.x

[14] Goldney, R.D., Fisher, L.J., Wilson, D.H. and Cheok, F. (2002) Mental Health Literacy of Those with Major Depression and Suicidal Ideation: An Impediment to Help Seeking. Suicide and Life-Threatening Behavior, 32, 394-403. http://dx.doi.org/10.1521/suli.32.4.394.22343

[15] Furnham, A. and Blythe, C. (2012) Schizophrenia Literacy: The Effect of Direct Experience with the Illness. Psychiatry Research, 198, 18-23. http://dx.doi.org/10.1016/j.psychres.2011.12.025

[16] American Psychiatric Association (2000) Diagnostic and Statistical Manual of Mental Disorders. Fourth Edition, Text Revision, American Psychiatric Association, Washington DC. http://dx.doi.org/10.1176/appi.books.9780890423349

[17] Lecrubier, Y., Sheehan, D.V., Weiller, E., Amorim, P., Bonora, I., Sheehan, K.H., et al. (1997) The Mini International 
Neuropsychiatric Interview (MINI). A Short Diagnostic Structured Interview: Reliability and Validity According to the CIDI. European Psychiatry, 12, 224-231. http://dx.doi.org/10.1016/S0924-9338(97)83296-8

[18] Cheung, Y.T., Ong, Y.Y., Ng, T., Tan, Y.P., Fan, G., Chan, C.W., et al. (2015) Assessment of Mental Health Literacy in Patients with Breast Cancer. Journal of Oncology Pharmacy Practice, In Press. http://dx.doi.org/10.1177/1078155215587541

[19] Deen, T.L. and Bridges, A.J. (2011) Depression Literacy: Rates and Relation to Perceived Need and Mental Health service Utilization in a Rural American Sample. Rural Remote Health, 11, 1803.

[20] Palazzo, M.C., Dell’Osso, B., Altamura, A.C., Stein, D.J. and Baldwin, D.S. (2014) Health Literacy and the Pharmacological Treatment of Anxiety Disorders: A Systematic Review. Human Psychopharmacology: Clinical and Experimental, 29, 211-215. http://dx.doi.org/10.1002/hup.2397

[21] Angermeyer, M.C. and Matschinger, H. (2004) Public Attitudes towards Psychotropic Drugs: Have There Been any Changes in Recent Years? Pharmacopsychiatry, 37, 152-156. http://dx.doi.org/10.1055/s-2004-827169

[22] Priest, R.G., Vize, C., Roberts, A., et al. (1996) Lay People’s Attitudes to Treatment Campaign Just before Its Launch. British Medical Journal, 313, 858-859. http://dx.doi.org/10.1136/bmj.313.7061.858 